\title{
ANÁlISE DE PATOLOGIAS EM OBRAS PÚBLICAS EDIFICADAS EM ESTRUTURAS DE AÇO, APLICANDO TECNOLOGIA BIM COMO PROPOSTA DE REPARAÇÃO.
}

\author{
L. P. TEIXEIRA. ${ }^{1 *}$, R. A. RIBAS ${ }^{2 * *}$ \\ * cteixeiraengenharia@hotmail.com \\ **rovadavia@ufop.edu.br
}

\begin{abstract}
1. Programa de Pós Graduação em Engenharia Civil. Departamento de Engenharia Civil, Escola de Minas, Universidade Federal de Ouro Preto, Ouro Preto, Brasil.

2. Programa de Pós Graduação em Engenharia Civil. Departamento de Engenharia Civil, Escola de Minas, Universidade Federal de Ouro Preto, Ouro Preto, Brasil.
\end{abstract}

\begin{abstract}
RESUMO
O objetivo do artigo é buscar através da tecnologia Building Information Modeling, o BIM, uma solução prática para sanar patologias em edificações públicas estruturadas em aço. A metodologia se baseia em um levantamento in loco, onde o resultado da avaliação e os projetos de construção são inseridos em uma plataforma com acesso a internet por meio de tabelas descritivas que podem ser aplicadas ao trabalho colaborativo com a finalidade de apresentar ações e indicar terapias corretivas, bem como a elaboração de um modelo de programa de manutenção preventiva, visando à redução de custos de manutenção e assistência nas decisões de reparo e tratamento das construções.
\end{abstract}

Palavras-chave: Building Information Modeling; trabalho colaborativo; patologias em edificações; redução de custos redução. 


\section{INTRODUÇÃO}

A construção de obras públicas contribui para o desenvolvimento da infraestrutura urbana e favorece o crescimento das cidades. A utilização do aço é muito comum nesses empreendimentos, pois além da praticidade na montagem, também se há rapidez em sua execução se comparadas aos demais tipos construtivos.

Em alguns momentos, a administração pública não se atenta para a proteção do patrimônio e do interesse social, onde a falta de manutenção, torna-se um aglomerado de patologias ocasionadas por falhas de projeto, execução inadequada da obra ou falta de manutenção periódica.

O Building Information Modeling (BIM) é o sistema pelo qual se armazenam virtualmente todas as informações, arquitetônicas estruturais, hidro sanitárias ou quaisquer outras pertinentes a uma determinada edificação, o que torna essa tecnologia uma ferramenta promissora para a construção ou a manutenção de estruturas e edificações. O conjunto interativo de processos, políticas e tecnologias provenientes desse meio produz uma abordagem para gerenciar projetos essenciais à construção e dados em formato digital, que vão se perpetuar durante toda vida útil do edifício por meio de um banco de dados, que podem ser geométricos ou não geométricos (London; Gu, 2010, apud Santos, 2017, p.33).

O conjunto interativo de processos, políticas e tecnologias provenientes desse meio produz uma abordagem para gerenciar projetos essenciais à construção e dados em formato digital, que vão se perpetuar durante toda vida útil do edifício por meio de um banco de dados. Podemos notar que o BIM aplicado em uma visão estreita corresponde somente ao modelo digital da edificação enquanto que a visão ampla envolve aspectos funcionais, documentais, técnicos, organizacionais e legais. Ele pode ser usado na fase de planejamento, construção, operação ou até mesmo na reforma de uma construção, tendo-se com isso a minimização dos erros gerados pelas divergências encontradas na fase de execução do projeto. Nos últimos anos, o uso do BIM tem se tornado mais difundido devido à acessibilidade à informação que a plataforma digital oferece aos responsáveis técnicos, proprietários, clientes e construtores do empreendimento. $\mathrm{O}$ armazenamento de informações interdisciplinares dentro de um modelo virtual de construção facilita o compartilhamento de conhecimento e a comunicação, integrando práticas que antes eram mal articuladas e reduzindo a má qualidade de informações presentes nos campos de obras (Volk; Stengel; Schultmann, 2014, apud Santos, 2017, p.33).

Os softwares BIM podem ser agrupados de acordo com a finalidade da aplicação. Existem softwares para modelagens arquitetônica, elétrica, hidráulica, estrutural, gestão da construção, análises e simulações do desempenho energético da edificação, gestão de instalações, sistemas georreferenciados, dentre outros (Santos, 2017).

Dessas normas, quatro foram publicadas (partes 1, 2, 3 e 7). No entanto as partes 4, 5 e 6 estão sendo discutidas. A criação das normas está linearmente acompanhando as demandas de alguns órgãos públicos brasileiros que estão iniciando a solicitação de projetos com a tecnologia BIM. A referência internacional utilizada para a criação da norma Brasileira foi a ISO/PAS 12.006-2, a qual, divide a estrutura BIM em sete níveis básicos" de classificação conforme é mostrado na Tabela 1 (Silva; Amorim, 2011, apud Santos, 2016, p. 40).

Tabela 1 - Norma Brasileira de Classificação das Informações BIM nos Processos de Construção Civil

\begin{tabular}{|l|l|c|c|}
\hline Número & Nome & $\begin{array}{c}\text { Data de } \\
\text { Publicação }\end{array}$ & Descrição \\
\hline
\end{tabular}




\begin{tabular}{|c|c|c|c|}
\hline $15965-1$ & Parte 1. Terminologia & $14 / 08 / 2011$ & $\begin{array}{l}\text { Define a terminologia, os princípios do } \\
\text { sistema de classificação e os grupos de } \\
\text { classificação para o planejamento, projeto, } \\
\text { gerenciamento, obra, operação e } \\
\text { manutenção de empreendimentos da } \\
\text { construção civil. }\end{array}$ \\
\hline $15965-2$ & \begin{tabular}{c|} 
Parte 2. \\
Características dos \\
Objetos de Construção
\end{tabular} & $10 / 08 / 2012$ & $\begin{array}{l}\text { Define as terminologias, o sistema de } \\
\text { classificação e os grupos de classificação } \\
\text { relativos às características dos objetos da } \\
\text { construção. }\end{array}$ \\
\hline $15965-3$ & $\begin{array}{l}\text { Parte 3. Processos de } \\
\text { Construção }\end{array}$ & $16 / 12 / 2014$ & $\begin{array}{l}\text { Apresenta a estrutura de classificação que } \\
\text { define os processos da construção, para } \\
\text { aplicação na tecnologia de modelagem da } \\
\text { informação da construção, pela indústria } \\
\text { de AEC. }\end{array}$ \\
\hline $15965-4$ & $\begin{array}{l}\text { Parte 4. Recursos de } \\
\text { Construção }\end{array}$ & & Em desenvolvimento \\
\hline $15965-5$ & $\begin{array}{c}\text { Parte 5. Resultados } \\
\text { Construção. }\end{array}$ & & Em desenvolvimento \\
\hline $15965-6$ & $\begin{array}{c}\text { Parte 6. Unidades de } \\
\text { Construção }\end{array}$ & & Em desenvolvimento \\
\hline $15965-7$ & $\begin{array}{l}\text { Parte 7. Informação da } \\
\text { Construção }\end{array}$ & $01 / 12 / 2015$ & $\begin{array}{l}\text { Apresenta a estrutura de classificação que } \\
\text { define as informações (ou dados } \\
\text { referenciados e utilizados durante o } \\
\text { processo de criação e manutenção de um } \\
\text { objeto construído) para aplicação na } \\
\text { tecnologia de modelagem da informação } \\
\text { da construção, pela indústria de AEC. }\end{array}$ \\
\hline
\end{tabular}

Para implantar o sistema BIM em uma determinada empresa, deve-se preliminarmente começar pelos fornecedores e clientes, devendo esses usuários passar por uma readaptação. O Departamento de Inovações do Negócio e Habilidades do Reino Unido (BIS) desenvolveu um modelo de maturidade da plataforma BIM, com níveis de 0 a 3 , classificando o grau de implantação dos softwares na indústria da construção em patamares mundiais. Nota-se que grande parte das empresas ainda está trabalhando no nível um e as demais atuando em benefícios relativos ao nível dois (Santos, 2016). 


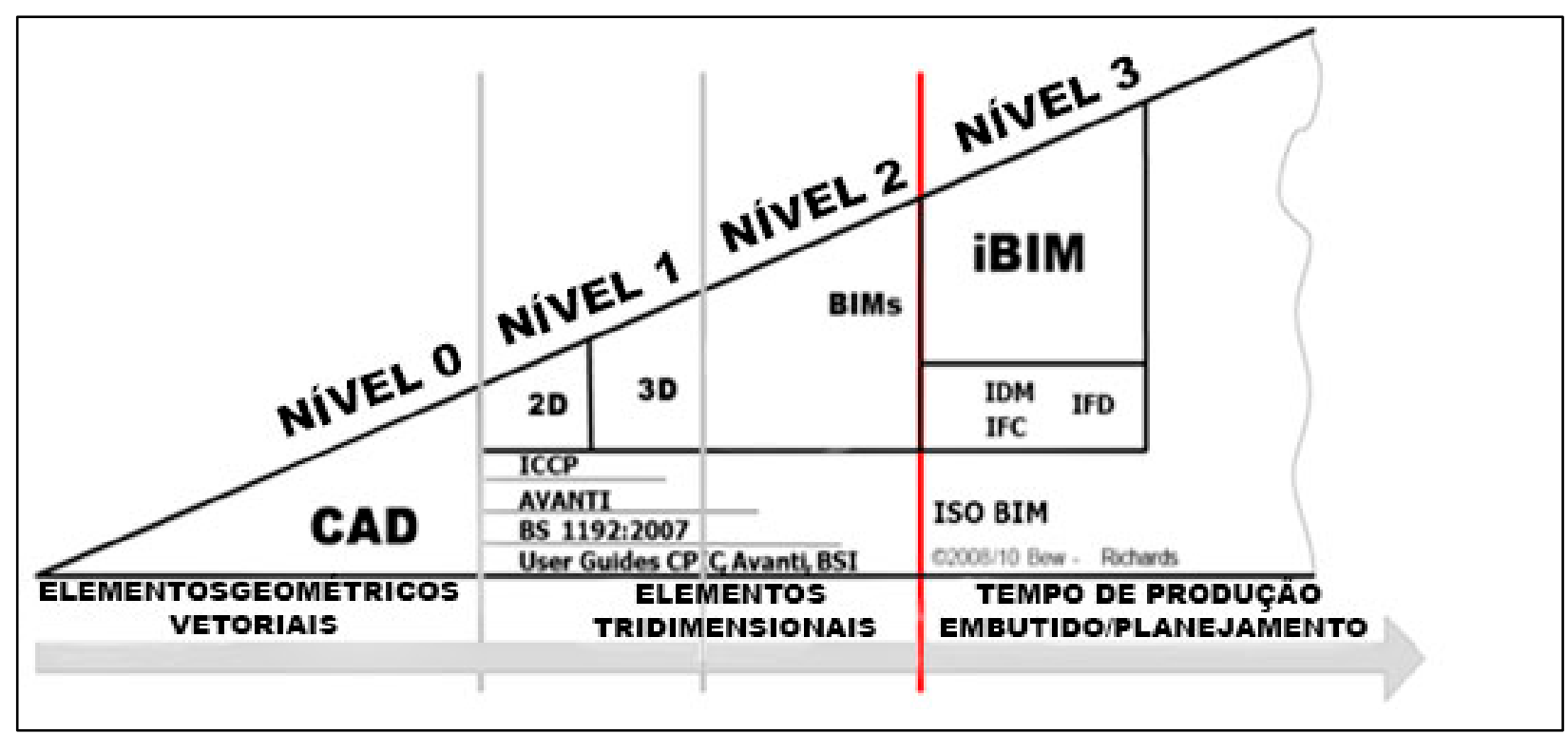

Figura 1. Níveis de Maturidade do Sistema BIM

A difusão da tecnologia BIM entre os profissionais ainda é restrita, sendo poucos os que possuem domínio integral da matéria, ressaltando-se que a entrada do BIM no país deu-se, primeiramente, por meio da área acadêmica, conforme destaca (Kassem; Amorim 2015, apud Souza 2017, p. 90).
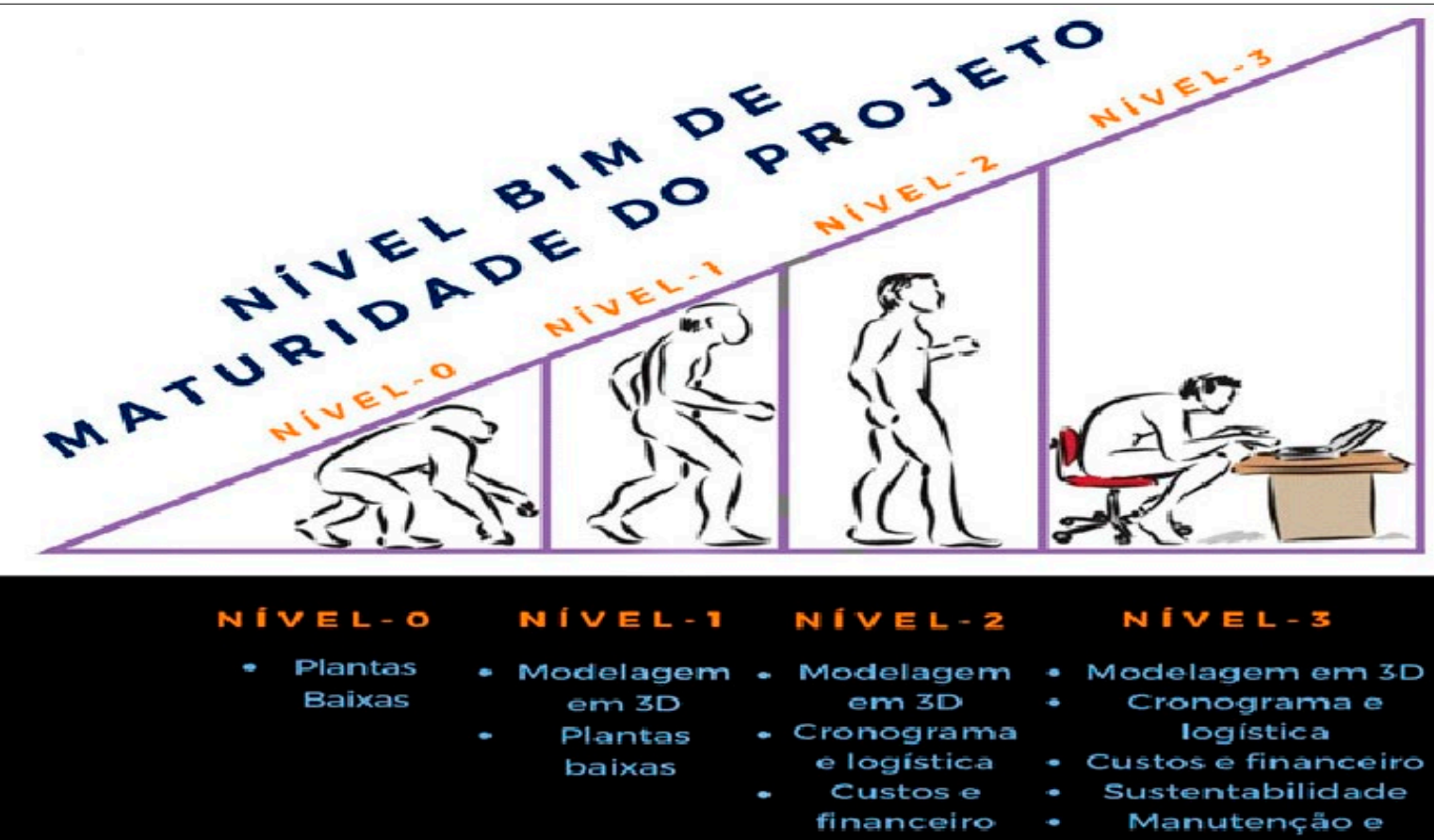

N I VEL - $\mathbf{3}$

Figura 2. Níveis de Maturidade do Sistema BIM

Em 5 de junho de 2017 ocorreu a publicação do Decreto da Presidência da República, que institui o Comitê Estratégico de Implementação do Building Information Modelling (Souza, 2017), representando uma iniciação no meio público brasileiro. Em 16 de maio do ano de 2018, o governo federal, fez o lançamento de estratégias a fim de promover a inovação na construção 
civil, sendo que em 17 de maio de 2018 foi instituído o decreto sob o número 9.377 denominado Estratégia BIM BR, esta por sua vez, tem a finalidade de promoção de um ambiente passível de investimentos em BIM no país e é representado por um colegiado (Brasil, 2018). Pode-se notar que no âmbito da legislação brasileira tem-se grande amparo normativo estruturado por um comitê interdisciplinar para fins de implantação da tecnologia BIM nos entes público e privado do país, razão pela qual, torna-se importante a busca pelo conhecimento e aplicação dessa metodologia tecnológica na engenharia nacional.

\section{MATERIAL E MÉTODOS}

O estudo se baseou na análise de uma edificação pública estruturada em aço, onde se teve a utilização de trabalhos colaborativos em plataformas BIM por meio da hospedagem em uma nuvem virtual, desta forma uma equipe multidisciplinar teve acesso ao banco de dados para programar a manutenção e o reparo deste imóvel direcionando os serviços de maior urgência como os preliminares para reparo numa possível obra de intervenção.

É utilizada uma plataforma denominada Trimble Connect, que permite que haja uma colaboração entre os vários projetistas de engenharia e construção. Acessível via desktop, mobile ou web, o Trimble Connect permite que os usuários visualizem, compartilhem e acessem informações do projeto de qualquer lugar, a qualquer momento. $\mathrm{O}$ estudo se dividiu em cinco etapas, sendo elas:

1) É feito uma visita in loco da edificação pública onde se é levantado as patologias existentes na estrutura.

2) Através do sistema de georreferenciamento onde se utiliza um sistema de coordenadas cartesianas denominado Universal Transversa de Mercator (UTM) é feito o mapeando as patologias decorrentes do sistema estrutural adotado e da falta de manutenção.

3) São criadas tabelas descritivas com o grau de urgência de manutenção de cada patologia, indicando-se suas causas e propondo-se soluções para sua reparação, bem como para prevenção de falhas futuras.

4) A análise é feita segundo o critério do Instituto Brasileiro de Avaliações e Perícias de Engenharia onde A avaliação pode ser classificada em grau crítico, regular ou mínimo, conforme o seguinte roteiro.

5) Com o grau de urgência de cada patologia definido e sua localização estabelecida geodesicamente, se é utilizado a tabela descritiva para indicar a melhor solução para sanar aquele problema.

\section{RESULTADOS E DISCUSSÕES}

Nesse artigo analisa-se uma edificação estruturada em aço, situada na cidade de Mariana, MG, é feito um mapeando das patologias decorrentes do sistema estrutural adotado e da falta de manutenção, indicando-se suas causas e propõem-se soluções para sua reparação, bem como para prevenção de falhas futuras. São criadas tabelas descritivas com o grau de urgência de manutenção de cada patologia, e também sua localização geográfica georreferênciada para seu acesso in loco, que podem ser utilizadas, posteriormente, em trabalhos colaborativos em plataformas BIM por meio da hospedagem em nuvem virtual. A análise é feita segundo o critério 
do Instituto Brasileiro de Avaliações e Perícias de Engenharia o IBAPE. A avaliação pode ser classificada em GRAU CRÍTICO, REGULAR ou MÍNIMO, conforme o seguinte roteiro: GRAU CRÍTICO: Dano que envolve risco iminente a saúde humana e; ou dano irreparável ao meio ambiente. GRAU REGULAR: Dano que implica em restrição aos usos mais prováveis do imóvel. GRAU MÍNIMO: Pequeno dano de fácil reparação e influencia localizada e restrita IBAPE. É utilizada a plataforma Trimble Connect, que permite que haja uma colaboração entre os vários projetistas de engenharia e construção, ela é acessível via desktop, mobile ou web, o Trimble Connect permite que os usuários visualizem, compartilhem e acessem informações do projeto de qualquer lugar, a qualquer momento. Nessa importante ferramenta tem-se a possibilidade da colaboração das várias partes envolvidas no projeto, podendo-se armazenar um número vasto de informações e especificidades da obra permitindo a continuidade do projeto no caso de alguma mudança na equipe. Modelos em três dimensões (3D) feitos em SketchUp, Revit, ou convertidos em Industry Foundation Classes (IFC), podem ser visualizados em tempo real na plataforma da Trimble Connect. Outros arquivos, com extensões pdf, jpg, docx, xlsx e pptx podem ser vistos pelo navegador de forma a se criar uma biblioteca de cada empreendimento estudado (Trimble Connect, 2019).

Após a conclusão do estudo nos imóvel, são produzidas tabelas com um checklist da estrutura. Posteriormente, todas as informações coletadas são compartilhadas em uma nuvem na plataforma da Trimble Connect de forma a expandir o acesso das informações e promover a integração de profissionais.

\subsection{Edificação Pública Estruturada em Aço Na Cidade De Mariana, MG - Estudo de Caso}

A partir da década de 1990 edifícios de caráter institucionais estruturados em aço foram construídos na cidade de Mariana, e alguns deles até hoje possuem grande relevância na esfera municipal, como a sede da Prefeitura e o Terminal Rodoviário. Na época, tais intervenções causaram grande impacto sobre a paisagem urbana existente, de caráter histórico, essas construções constituem-se em estruturas arrojadas e de características atípicas às edificações já construídas na região. $\mathrm{Na}$ atualidade encontram-se outros modelos que se destacam e entre eles estão: a Escola Municipal Morro Santana, Centro Esportivo Arena Mariana, Centro de Convenções e a Unidade de Pronto Atendimento (UPA) São Pedro.

\subsubsection{Estudo de Caso Prefeitura Municipal de Mariana}

O edifício da Prefeitura Municipal de Mariana, cuja concepção arquitetônica é do Arquiteto Rafael Fogli Diniz Ribeiro, foi inaugurado em 16 de julho de 1996, durante o tricentenário da cidade de Mariana. Está localizado na Praça Juscelino Kubitschek, s/n.

A edificação é um ponto de passagem entre a região central e as regiões periféricas da cidade. Seu perímetro é composto por imóveis de uso residencial e comercial e encontra-se em suas proximidades a estação ferroviária de Mariana, razão pela qual, a prefeitura também tem seu público turístico ativo (Rocha, 2007). 


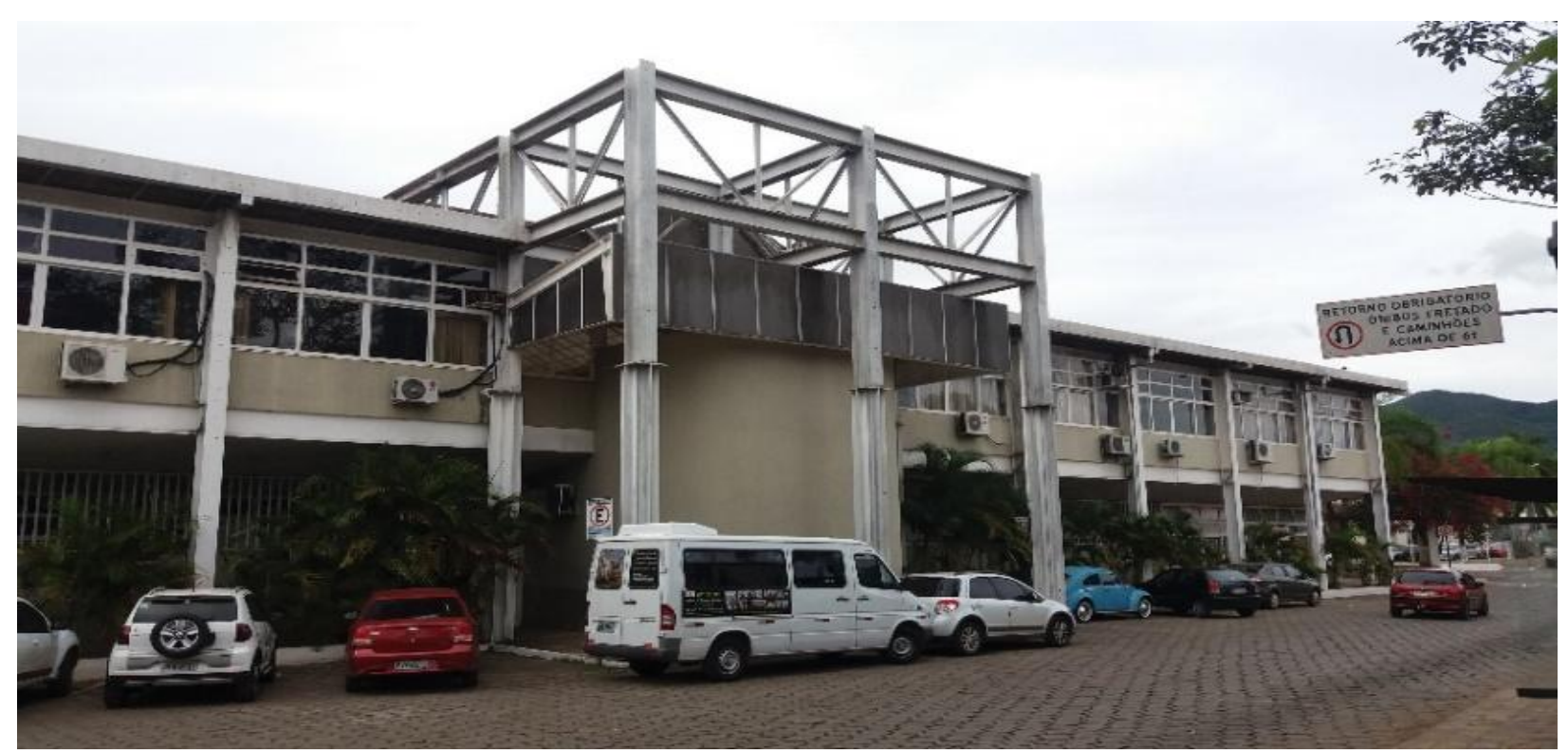

Figura 3. Imóvel objeto do estudo

As edificações vizinhas possuem gabarito de dois pavimentos, sendo a área de baixo potencial construtivo devido ao tombamento do centro histórico de Mariana pelo Instituto do Patrimônio Histórico e Artístico Nacional (Iphan, 2019).

As atividades que são manejadas na edificação se dividem da seguinte forma: os serviços destinados ao cidadão estão locados no pavimento inferior e as atividades de ordem administrativa localizam-se no pavimento superior. No pavimento térreo da edificação têm-se dois acessos de entrada, sendo eles situados na parte leste e oeste do imóvel. No $1^{\circ}$ pavimento estão localizados setores como a Controladoria, Fazenda, Instalações Sanitárias, Contabilidade e Tesouraria, Protocolo, Receita Imobiliária e Secretaria de Obras. No segundo pavimento do imóvel estão localizados os Gabinetes do Prefeito e do Vice-Prefeito, Procuradoria, Comunicação e Departamento de Pessoal, Licitação e Compras, Administração, Planejamento Urbano e uma cozinha. O imóvel está situado em um terreno com área aproximada de $2.000 \mathrm{~m}^{2}$. A projeção da edificação ocupa $950 \mathrm{~m}^{2}$, sendo o restante destinado a estacionamento e calçadas. Os dois pavimentos somam um total de $2.150 \mathrm{~m}^{2}$, sendo $820 \mathrm{~m}^{2}$ do pavimento térreo, $1.230 \mathrm{~m}^{2}$ do segundo pavimento. $\mathrm{O}$ restante, $100 \mathrm{~m}^{2}$, corresponde às circulações verticais das escadas de incêndio e da escada central (Rocha, 2007). No envoltório da edificação há predominância de vegetação de pequeno porte, do tipo arbustivo ou gramíneo. Em relação à sua concepção, o edifício da Prefeitura Municipal de Mariana foi resultado de uma intervenção sobre a edificação da antiga estação rodoviária municipal existente, caracterizado como uma reforma e ampliação do imóvel que posteriormente fora utilizado como órgão do executivo. A edificação da prefeitura tem características marcantes como o pé direito elevado no hall do segundo pavimento e cobertura em policarbonato de aparência translúcida. Seu sistema estrutural é constituído por pilares de concreto, no primeiro pavimento, existentes desde os tempos em que a edificação era utilizada como rodoviária, trabalhando conjuntamente com estruturas de pilares e vigas em aço do segundo pavimento que tem espaçamento uniforme entre si de cinco metros longitudinalmente e de oito metros transversalmente. Essa estrutura foi adicionada para que fosse construído o segundo andar da edificação a título de ampliação. Quanto ao fechamento, lajes, esquadrias, coberturas e forros, têm-se: fechamento em alvenaria de tijolos cerâmicos; laje pré-fabricada utilizando tijolos cerâmicos e vigotas de concreto; esquadrias metálicas; cobertura em telhas cerâmicas e parte em policarbonato; forro em policloreto de polivinila PVC. 


\subsection{Avaliação da Prefeitura Municipal de Mariana}

Como meio de avaliação das edificações foram realizadas investigações exploratórias através de diversas visitas técnicas aos imóveis. Entre os elementos inspecionados têm-se: pilares, vigas, coberturas, ligações, fechamentos, placas de base, lajes e demais detalhes que são expostos a seguir. Essa avaliação teve como objetivo identificar patologias existentes e suas causas, de forma a expor o estado de manutenção dessas edificações, assim como citar medidas de reparação e prevenção.

\subsubsection{Prefeitura Municipal de Mariana}

De sistema estrutural constituindo o segundo pavimento em aço e o primeiro pavimento em concreto, cobertura em telha cerâmica cor vermelha e hall central coberto em policarbonato translúcido, no edifício da Prefeitura Municipal de Mariana, percebe-se a busca pelo aproveitamento da estrutura anteriormente existente, por meio da utilização do aço como solução, que de certo modo se torna atrativa. Com pé direito elevado no segundo pavimento são aplicados perfis I, H e U em toda a sua estrutura, notando-se a praticidade ao se adotar o aço em reformas de maior porte.

\subsubsection{Avaliação da Metodologia Construtiva}

A metodologia construtiva em aço foi inserida como alternativa de expansão desse imóvel para sua utilização como sede da prefeitura da cidade de Mariana. O uso desse tipo de estrutura proporciona vários dos benefícios citados anteriormente, podendo-se destacar: flexibilidade e leveza da estrutura, além da possibilidade de ampliação da edificação sem grande intervenção na estrutura antiga.

Durante qualquer obra de reforma ou modificação da estrutura de uma edificação é de extrema importância a redução da quantidade de carga a ser aplicada na estrutura original, assim como a flexibilização para alterações estruturais, e só a estrutura em aço permite de maneira eficaz e rápida uma alteração abrupta na concepção estrutural do imóvel. Nessa edificação essa utilização foi adotada.

\subsubsection{Patologias Detectadas}

Durante a inspeção foram detectadas patologias, podendo-se notar que em sua maioria são de ordem geral e estética. Também se buscou avaliar o estado de manutenção do edifício no intuito de encontrar a origem das manifestações patológicas, propondo-se soluções corretivas ou aprimoramento da manutenção das estruturas.

$\mathrm{O}$ descascamento da pintura da estrutura de aço foi uma das patologias mais encontradas. Como essa patologia ocorre devido à perda de aderência entre a película de tinta e a estrutura, ou quando existem demasiadas demãos de tintas no elemento, nota-se que ao fundo há uma película de tinta vermelha intacta, a segunda demão não se aderiu à superfície sobre a qual foi aplicada (Figura 4). Citam-se como prováveis causas o uso de tinta incompatível com a já aplicada.

Como tratamento, recomenda-se que em todos os elementos onde haja camada de tinta solta ou mal aderida devem ter essa camada totalmente removida de sua superfície, utilizando-se para a escarificação a lixadeira ou espátula, e posteriormente deve-se aplicar a pintura de correção de modo a se garantir a estanqueidade da estrutura em relação a patologias de ordem estrutural.

A corrosão eletroquímica, que é favorecida pela presença de umidade, e fezes de pombos tem bastante ocorrência em placas de base onde o nível de instalação é próximo a canteiros ou a solos úmidos com a presença de vegetação (gramíneas e sebáceas). 


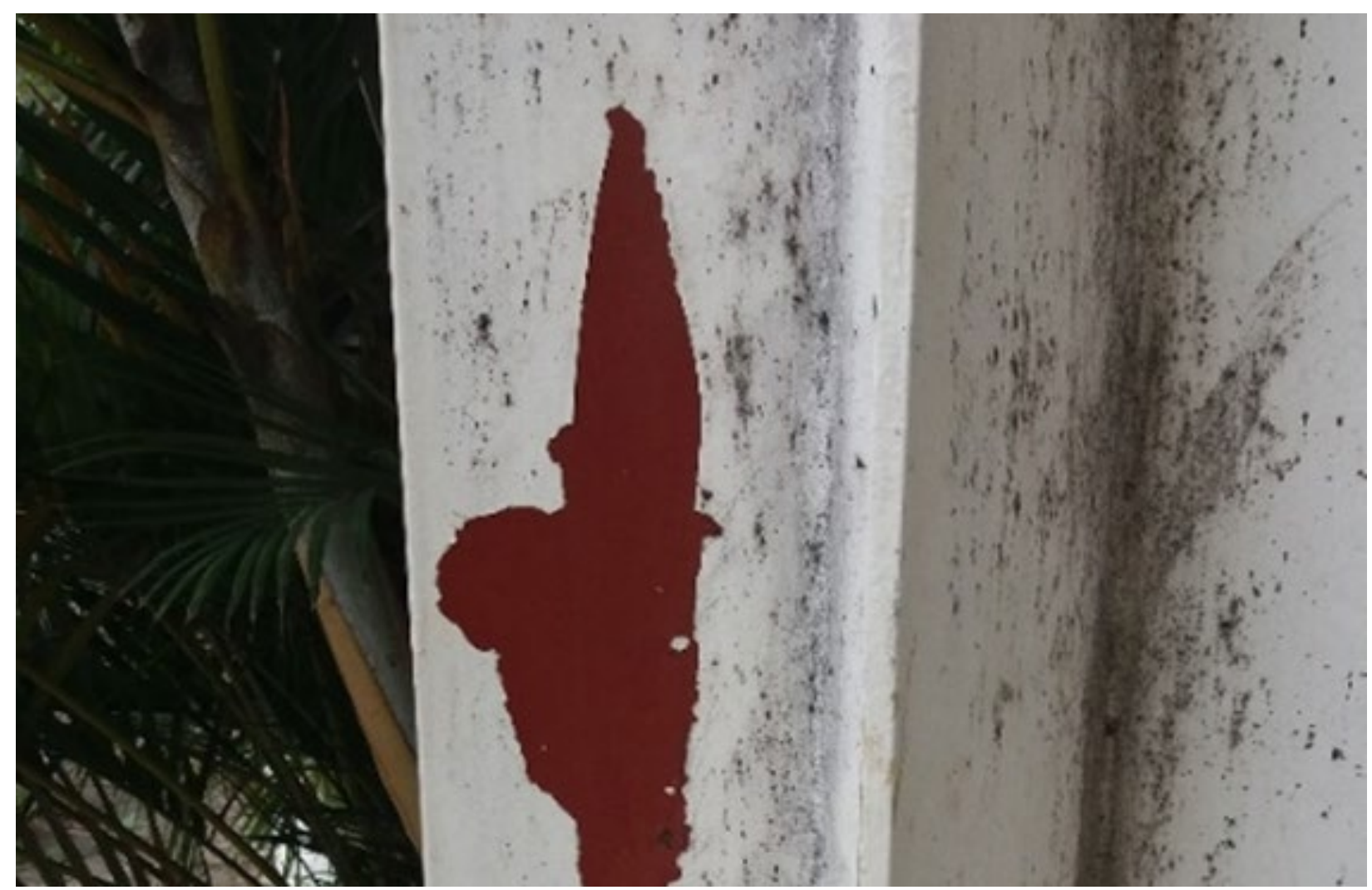

Figura 4. Patologia em pintura detectada na estrutura

Nota-se de forma constante processos corrosivos em desenvolvimento na base dos pilares devido a essa característica

Como tratamento, indica-se revestir as bases desses pilares com manta impermeabilizante de base betuminosa, e posteriormente aplicar concreto em sua volta no intuito de eliminar áreas que tendem ao acúmulo de água, assim como promover uma limpeza rotineira do local. A aplicação de uma argamassa com impermeabilizante também seria uma solução que faria com que a incidência da pilha eletroquímica se tornasse insignificante, reduzindo o ataque patológico.

O contato com superfícies de concreto onde não está prevista a preparação da estrutura para o escoamento da água proveniente da chuva ou, por ventura, de alguma lavagem da fachada, faz com que muitos locais sejam propícios para a corrosão em frestas. Encontra-se essa modalidade de patologia em várias janelas do segundo pavimento e também é bastante evidente na porta pertencente à entrada do hall do primeiro pavimento.

Pode-se perceber que a fresta entre a esquadria da porta e o piso de concreto é muito estreita, favorecendo a presença de umidade no local e o desenvolvimento do processo corrosivo Um tratamento indicado para esse caso é rever a proximidade entre as esquadrias para que a pilha eletroquímica não tenha recorrência no local.

Para evitar umidade nas esquadrias devido ao ar condicionado, a parte de saída da água proveniente da troca de calor dos ambientes deve ser encanada de forma que a mesma não tenha contato direto com a estrutura. No que se refere à estrutura de aço da fachada, pode-se indicar uma reforma com pintura a base de poliuretano, haja vista que a mesma está com a vida útil comprometida e há uma grande presença de descascamentos e escurecimento de sua tonalidade, fator esse que requer uma repintura de toda a estrutura.

O entupimento de calhas e tubulação de captação de água pluvial com os detritos gerados pelos pombos é fator que ocasiona uma série de patologias. A presença dessa ave nos ambientes públicos é tipicamente notada, pois, em geral, não conta-se com um esquema adequado de 
manutenção preventiva e periódica. Ocorre que as fezes dos pombos favorecem a corrosão e tornam-se uma grande ameaça à integridade das estruturas. Nota-se um grande acúmulo de fezes na estrutura assim como o início do processo de corrosão em frestas nas esquadrias. Mesmo tendo sido instaladas telas metálicas, para impedir a entrada dessas aves nos nichos entre a estrutura e a cobertura, notam-se a presença delas acima das telas.

Para o tratamento desses problemas observa-se que no mercado há inúmeros repelentes de pombos que podem ser instalados na cobertura da estrutura de modo a eliminar a presença dessa ave. O uso correto de telas e a colocação de pontas de aço em alguns locais também podem afastá-las da estrutura. Em relação às calhas, tem-se que é necessária uma manutenção preventiva de modo a evitar o entupimento das mesmas. Recomenda-se sua limpeza periódica, bem como das entradas da tubulação da água pluvial evitando-se patologias como as notadas.

Uma manutenção não planejada pode fazer com que componentes da estrutura tenham sua camada protetora comprometida, e com isso, a mesma fica susceptível a inúmeras patologias que podem gerar futuras pilhas eletroquímicas ocasionando estados de corrosão. Em relação à pintura da estrutura de aço dessa construção, podem ser vistas patologias como casca de laranja, descascamento e impregnação de abrasivos. Destaca-se a existência de impregnação do abrasivo na pintura em um pilar próximo à rua onde se tem alta presença de partículas em suspensão, razão pela qual o lugar é propício para essa patologia da tinta.

Posteriormente efetuar uma repintura de todos os componentes com uma tinta à base de poliuretano, haja vista que são elementos que sofrem a ação direta de intempéries e necessitam de uma correta aplicação de tinta de maior durabilidade da pintura devido à presença continua de umidade e partículas provenientes da poluição.

Para uma visão mais global da ocorrência das patologias, na Tabela 2 mostra-se a quantidade de focos de patologias detectados na edificação que são a corrosão uniforme, corrosão em frestas, impregnação do abrasivo e descascamento de pintura. Como tratamento dessas patologias recomenda-se a escarificação e limpeza da estrutura, removendo-se totalmente os detritos e restos de tinta.

Tabela 2. Focos de patologias detectadas na Prefeitura Municipal de Mariana

\begin{tabular}{|l|l|l|}
\hline Patologia & Focos detectados $\left(\mathbf{n}^{\mathbf{0}}\right)$ & Percentual (\%) \\
\hline Descascamento de Pintura & 22 & 45 \\
\hline Impregnação do Abrasivo & 17 & 35 \\
\hline Corrosão em Frestas & 5 & 10 \\
\hline Corrosão Uniforme & 5 & 10 \\
\hline
\end{tabular}

\subsubsection{Inserção de dados na Plataforma BIM}

Conforme planejado, os dados obtidos durante a pesquisa são inseridos em uma plataforma BIM de forma a se produzir um acervo técnico ao qual o profissional responsável pela edificação pudesse ter acesso de forma ágil e útil para a tomada de decisões e programação de manutenção periódica. Dessa forma, é mostrada a seguir uma proposta de organização das pastas e apresentação dos anexos dentro da ferramenta do Building Information Modeling denominada Trimble Connect.

Na Plataforma Trimble Connect, nota-se que é possível organizar e compartilhar os dados da edificação com a equipe responsável pelo projeto, tendo esse profissional acesso às informações onde quer que ele esteja. Dessa maneira ele terá uma grande praticidade para sua tomada de decisões em relação ao combate das patologias ou mesmo sua prevenção. É criada uma pasta denominada Obras Públicas Mariana-MG para que se possa inserir o Anexo I referente ao edifício da Prefeitura Municipal de Mariana.

Também se é possível visualizar arquivos em formato PDF ou modelos 3D sem que seja necessária a instalação de nenhum software no dispositivo computacional utilizado. 

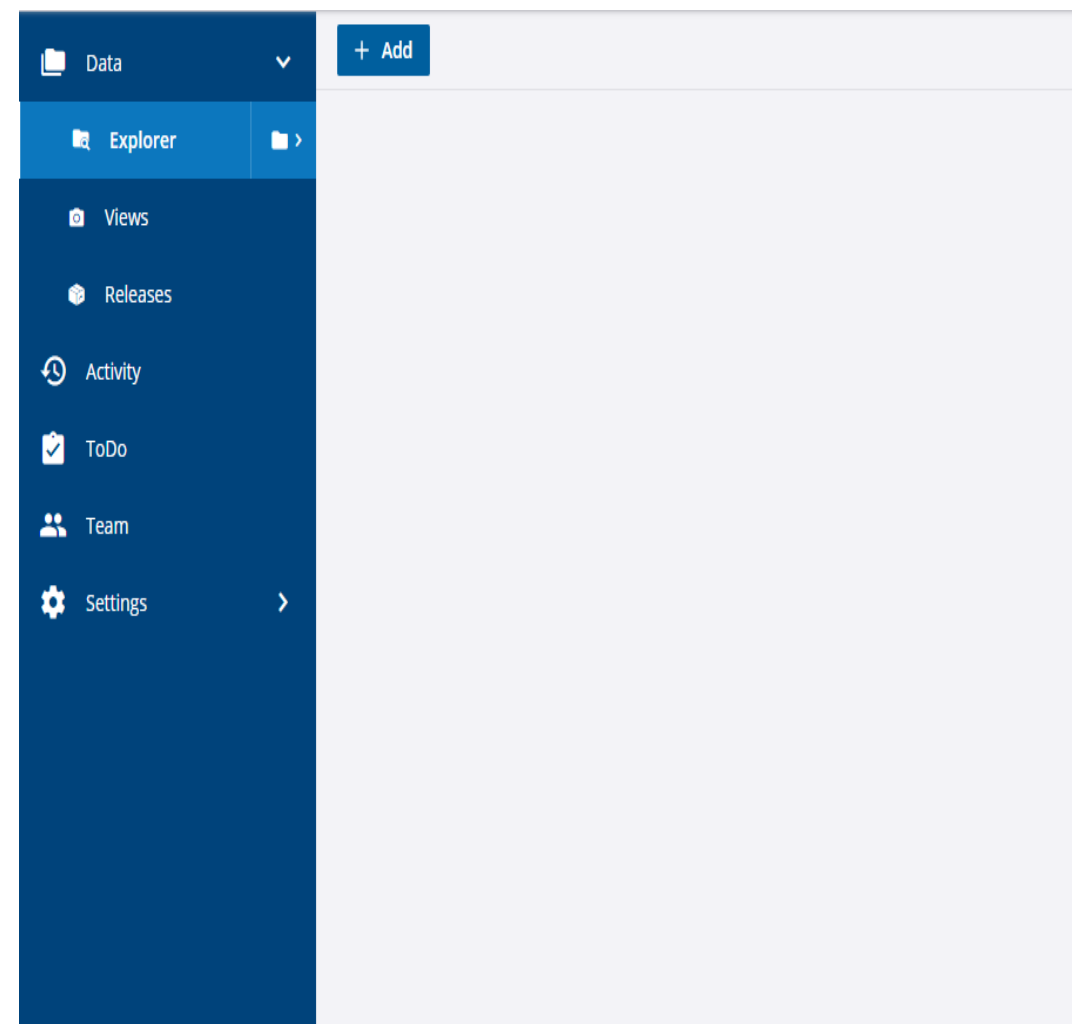

Drag \& drop to this folder or create

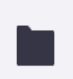

New folder

Group data and

assign permissions

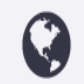

Map workspace

Manage your GIS

data collection

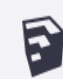

Sketchup model

Create Sketchup

model online

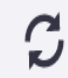

Download Sync Synchronise your project from your desktop

Nota-se que a maioria das patologias localizadas no imóvel é de cunho estético, e elas estão relacionadas a descascamentos de pintura e impregnação do abrasivo, resultantes, provavelmente, da aplicação de tinta inapropriada ou falhas na sua metodologia de aplicação, assim como a inobservância dos cuidados necessários para que fossem garantidas as características de estanqueidade da estrutura. Pode-se concluir, mediante a análise feita, que são patologias de simples correção e que não afetam o sistema estrutural da edificação podendo um programa adequado de manutenção ser aplicado periodicamente através do acervo técnico inserido na plataforma BIM, podendo sanar os problemas detectados. No entanto, caso não seja seguido esse programa de manutenção, as patologias podem vir a comprometer futuramente o desempenho da edificação. 


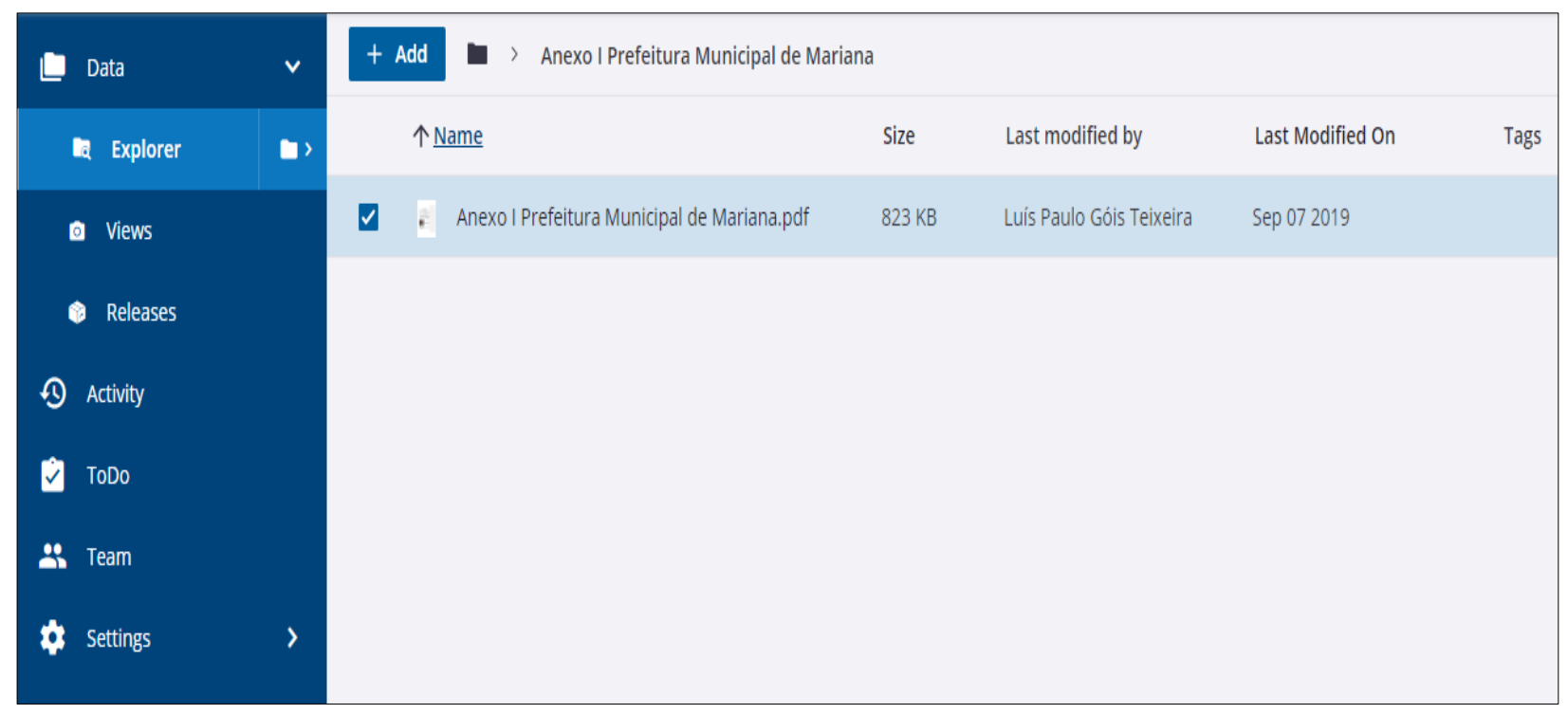

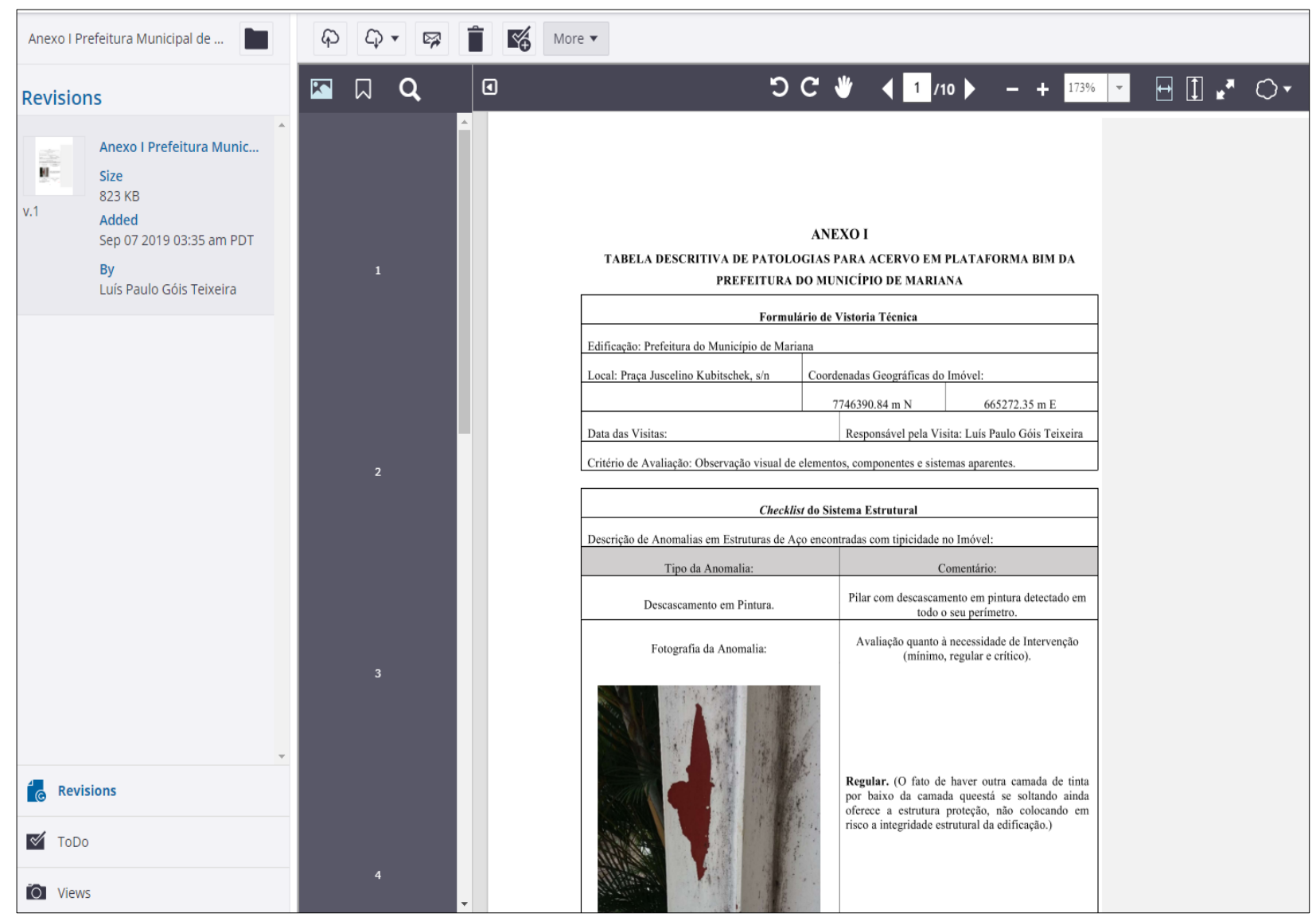



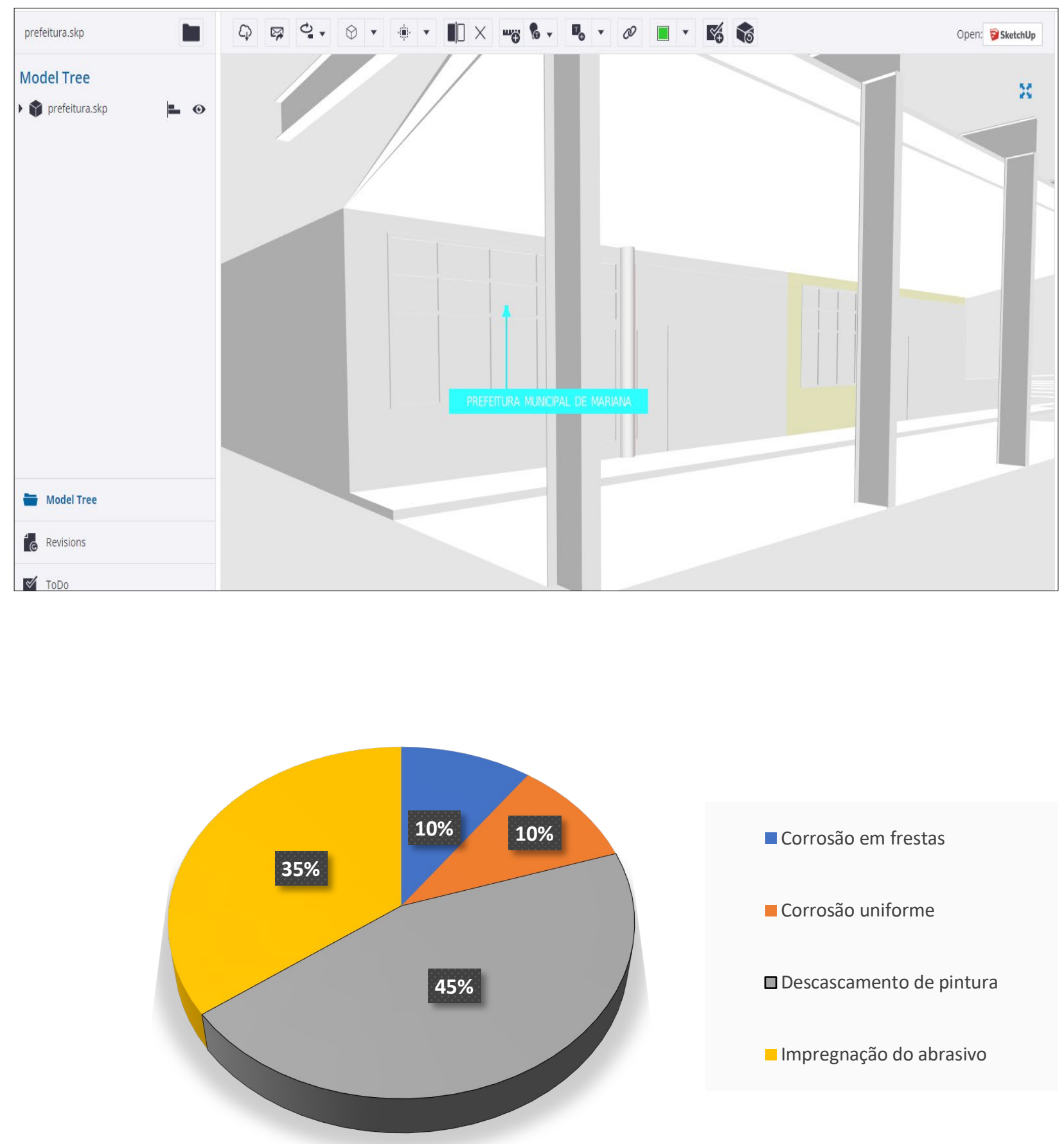

O gráfico acima demonstra o percentual de patologias encontradas na estrutura, claramente, se vê que em sua maioria, temos problemas de descascamento de pintura, onde inicialmente pode-se reparar de maneira mais simples e de forma menos onerosa. 


\section{CONCLUSÃO}

Nesta pesquisa podem-se notar os diversos tipos de patologias em estruturas de aço e seus respectivos tratamentos e, assim, entender como é importante à elaboração adequada de projetos bem como a manutenção dos imóveis edificados em aço, sendo também ressaltada a relevância de uma rápida e devida intervenção em caso de alguma manifestação patológica. $\mathrm{O}$ conhecimento das modalidades de patologias e seus tratamentos em edifícios públicos é uma importante maneira de contribuir para a prevenção desses processos que podem vir de projetos com falhas em detalhamentos. Destaca-se que uma eficaz solução seria o compartilhamento de informações entre os vários profissionais que estão inseridos nesse meio, através do uso da tecnologia BIM.

Justifica-se o uso dessa metodologia, uma vez que, quando há mudança de governo, grande parte dos profissionais são trocados e consequentemente há uma desorganização e dificuldade para o levantamento de dados referentes às edificações públicas, tornando a manutenção e projetos para essa finalidade precários ou muitas vezes inexistentes.

As pesquisas in loco de detalhes mostrados nos estudos de caso constituem uma forma de difundir o conhecimento e demonstrar ao profissional da construção estruturada em aço como essas patologias se manifestam e qual a melhor forma de prevenir e repará-las. Além disso, são necessários programas de prevenção que englobem manutenções realizadas periodicamente, independente do sistema estrutural adotado, para se evitar futuras intervenções radicais na estrutura, e o uso da tecnologia BIM permite que a patologia seja anotada em relatório compartilhado entre profissionais para que seja analisado seu reparo ou solução, reduzindo assim o tempo para ação de manutenção ou reparação. Destaca-se que o georreferenciamento é outra ferramenta que pode ser aplicada para que a patologia seja localizada de forma precisa na edificação.

\section{REFERÊNCIAS}

Brasil. Constituição Federal de 1988. Promulgada em 5 de outubro de 1988. Disponível em $<$ http://www.planalto.gov.br/ccivil 03/constituicao/constituicaocompilado.htm>. Acesso em 11 de janeiro de 2018.

Gu, N.; London, K. Understanding and facilitating bim adoption in the aec industry. Automation in construction, [s.1.], v. 19, n. 8, p. 988-999, dez. 2010.

Rocha, M. V. M. Avaliação pós-ocupação de edifício institucional estruturado em aço. O caso da sede da prefeitura municipal de Mariana, MG. Dissertação (mestrado em ciências da engenharia civil) - universidade federal de ouro preto. Ouro preto: ufop, 2007. $129 \mathrm{f}$.

Santos, S. Vantagens das ferramentas building information modeling - bim - no panorama do projeto de edificações no brasil. 2016. 126 f. Tese (doutorado em engenharia de produção) programa de pós-graduação strictu sensu em engenharia de produção da universidade paulista. São paulo: unip, 2016.

Santos, K. Gestão da manutenção de edificações com o BIM: enfoque nas manifestações patológicas de elementos de construção. 2017. 202 f. Dissertação (mestrado em engenharia civil) - centro tecnológico programa de pós-graduação em engenharia civil universidade federal do espírito santo. Vitória: UFES, 2017. 
Silva, J. C. B; Amorim, S.R.L. A contribuição dos sistemas de classificação para a tecnologia BIM - uma abordagem teórica in tic 2011 - anais do v encontro da tecnologia da informação na construção. Salvador, Bahia. 2011.

Souza, Ruymar, 1. Aplicabilidade da tecnologia BIM em projetos de estruturas metálicas. Dissertação (mestrado profissional em construção metálica) - universidade federal de ouro preto. Ouro preto: ufop, 2017. $151 \mathrm{f}$.

Trimble Connect enterprise. Trimble Connect: plataforma bim. 2.81. [s. L.], 2019. Disponível em $<$ https://connect.trimble.com/why-trimble-connect.html $>$. Acesso em 10 abril de 2019.

Iphan. Instituto do patrimônio histórico e artístico nacional. Brasília/DF. 2019. Disponível em:< http://portal.iphan.gov.br/> acesso em 06 de novembro de 2019.

Volk, R.; Stengel, j.; Schultmann, F. Building information modeling (BIM) for existing buildings - literature review and future needs. Automation in construction, [s.1.], v. 38, mar. 2014, p.109127. 